Article

\title{
Learning or Relaxing: How Do Challenge Stressors Stimulate Employee Creativity?
}

\author{
Yongbo Sun, Xiaojuan $\mathrm{Hu}$ * and Yixin Ding \\ Business School, Beijing Technology and Business University, Beijing 100048, China; \\ sunyb@th.btbu.edu.cn (Y.S.); 10011316553@st.btbu.edu.cn (Y.D.) \\ * Correspondence: 1730601056@st.btbu.edu.cn
}

Received: 19 February 2019; Accepted: 20 March 2019; Published: 25 March 2019

\begin{abstract}
As important situational factors in the workplace, challenge stressors play an important role in stimulating employee creativity. This study used self-efficacy and emotional exhaustion as intervening processes to delve into the impact of promotion and depletion mechanisms of challenge stressors on employee creativity. According to the theory of resource conservation, the study explores the moderating effect of learning and relaxing at work on the promotion and depletion mechanisms of challenge stressors. Fuzzy-set qualitative comparative analysis was conducted to analyze the effect of a combination of factors on employee creativity. A total of 240 valid paired-samples were collected from employees of three enterprises in information technology, finance, and evaluation services industries. This study drew the following conclusions. Challenge stressors have a direct positive effect on employee creativity, self-efficacy and emotional exhaustion have partial mediating effects on the relationship between challenge stressors and employee creativity, learning positively moderates the relationship between challenge stressors and self-efficacy, and qualitative comparative analysis reveals three configurations that improve employee creativity.
\end{abstract}

Keywords: challenge stressors; employee creativity; learning; relaxing; fuzzy-set qualitative comparative analysis

\section{Introduction}

Currently, researches on the workplace in Western focus on individual health [1] and well-being [2,3]. While China is in the fast catch-up phase, we place greater emphasis on organizational performance [4] and employee performance [5]; employee creativity is also vital to the sustainability of organizations and individuals. As an important situational factor in the workplace, how employee creativity can be activated through stress remains an important issue [6-8].

Challenge stressors refer to the pressures exerted by environmental conditions and job requirements that individuals believe can be overcome, which provide opportunities for individual growth and learning [9]. Since the concept of challenge stressors was proposed, most researches have focused on its aspirational effects, which can positively affect job satisfaction [10], job performance [8], etc. However, some scholars have argued that challenge stressors may include obstructive characteristics of stress in certain situations and produce negative results [11,12]. What is more, some scholars have also found that challenge stressors have no significant positive or negative effect on work outcomes, because the positive and negative effects offset each other [2]. Faced with these research conclusions, it is necessary to explore the impact of challenge stressors on employee creativity through the identification of underlying mechanisms. On the one hand, individuals have higher intrinsic motivation and confidence in their competence when they perceive challenge stressors to be within their own capabilities, and are more prone to generate creative ideas and behaviors [13]; on the other hand, challenge stressors can also result in the depletion of energy manifesting as strains such as 
anxiety and burnout [2,7], which are not conducive to employee creativity. Therefore, the first goal of this article is to explore how challenge stressors exert double-edged effects to employee creativity.

Prior researches on the mechanisms that moderate challenge stressors have focused on organizational and leadership factors, including organizational support [14], supervisor support [15], superior-subordinate relationships [8], and leadership styles [7]. However, the boundaries defining existing researches derive from relatively stable organizational environments or management traits. Compared to external factors, employees' internal factors, including individual skills, abilities, and behaviors, are more stable and controllable. Thus, rather than reflecting on the external environmental factors impacting upon employees, paying more attention to the internal conditions of staff is urgently required. Relaxation is a common individual response to counter stressful situations. It requires relatively low effort [16] and can temporarily alleviate negative emotions [17]. Individuals' learning in the process of coping with challenge stressors is also beneficial to employee creativity through acquiring effective work resources [18]. Accordingly, we also ask a second question about how employees self-regulate, by learning or relaxing, when facing challenge stressors.

The impact of challenge stressors on employee creativity may take several equivalent paths. Although quantitative methods can confirm the causal relationship between variables, it is difficult to exclude the existence of other explanatory antecedent conditions [19], such as other types of stressors. Our third question asks how to explain other factors that affect outcome variables that are not discussed in the quantitative model. As a result, based on the theoretical framework of the work requirement-resource model, we used self-efficacy and emotional exhaustion as mediating variables to investigate the promotion and depletion mechanisms of challenge stressors on employee creativity, and explored the moderating role of learning and relaxation at work in the relationship between challenge stressors, self-efficacy, and emotional exhaustion. Finally, we analyzed the combined paths of multiple factors affecting employee creativity using configuration theory.

\section{Theory and Hypotheses}

\subsection{Challenge Stressors and Employee Creativity}

Stressors are generated by interactions between the individual and their environment. Job stressors are environmental conditions and demands at work that tax individuals. Cavanaugh [20] divided job stressors into challenge stressors and hindrance stressors according to their properties, on the basis of previous studies. Challenge stressors refer to the stressful factors that have positive effects on individual work attitudes and behavior, such as workload, time pressure, job responsibility, and complexity, which can stimulate individuals to improve, grow, and develop their career. Meanwhile, hindrance stressors are stressful factors at work that have negative effects on individual work attitudes and behavior, such as role ambiguity, organizational politics, red rale, and job instability, which are generally viewed as thwarting personal growth and goal attainment [8].

Employee creativity refers to employees' abilities to generate novel and potentially valuable ideas at work, for products, services, concepts, and processes that differ from previous practices [21]. Employee innovation is often the result of a combination of environmental factors and individual characteristics. As one of the key elements of the work environment, workplace stress has an important impact on employee creativity. According to the stress cognitive interaction theory [22], employees consider challenge stressors as job demands that comprise achievable task goals and challenging job opportunities, after considering their resources and external conditions. External work requirements can motivate employees to renew themselves and change working environments, to promote the maximum matching between individuals and pressure situations [23]. Innovative behaviors will drive these changes [24]. Thus, we propose the following hypothesis.

Hypothesis 1. Challenge stressors positively relate to employee creativity. 


\subsection{Mediating Effect on Challenge Stressors and Employee Creativity}

\subsubsection{Self-Efficacy}

Self-efficacy is 'the judgment of an individual's ability to organize and perform certain behaviors and achieve desired results', which can be improved through enactive mastery, vicarious modeling, verbal persuasion, and arousal [13]. The emergence of stress is the result of the interaction between environmental stimulus and individual response. The individual's cognitive evaluation of a situational stimulus is the key to the generation of stress [25]. Challenge stressors mean that employees' perception of the job demands fall within their own ability, and this affects employees' self-efficacy through emotional arousal and verbal persuasion. For one thing, the challenging perception of stress arouses positive emotions of employees, enhancing employees' confidence in meeting work requirements and promoting employee self-efficacy [26]. Lepine [27] pointed out that challenge stressors can stimulate individuals' positive emotions and prompt them to adopt proactive or problem-solving coping strategies, such as exerting more efforts, meaning challenge stressors can play an important role in emotional arousal. For another, an organization's high work performance expectations indicate that the organization recognizes their ability and potential, and the 'Pygmalion effect' will enhance the self-efficacy of employees. Therefore, we posit that challenge stressors enhance employees' self-efficacy.

Furthermore, the three-element model of creativity proposes that individual creativity needs three factors: professional knowledge, creative thinking skills, and intrinsic motivation [28]. The higher the level of any one factor, the greater the individual's creativity. So, employees with high self-efficacy can enhance their creativity through creative thinking skills and intrinsic motivation. First, positive emotions can enhance creativity [29]. This means that a positive and optimistic mood is more conducive to creativity than a negative mood. Employees with strong confidence in their ability to complete tasks usually maintain a positive and optimistic attitude, as well as a higher sense of well-being at work. Second, self-efficacy enables employees to use novel and creative methods when solving problems. They actively search for useful information and resources outside their role or organization and acquire new skills. Third, self-efficacy drives employees to set higher mission goals and concentrate on the goal achievement process. Intrinsic motivation and self-confidence stimulate creativity and drive higher performance. Therefore, we posit that self-efficacy stimulates employee creativity.

Challenge stressors are the perception of employees' matching of situational requirements and their own abilities. In the workplace, employees tend to regard these requirements more as opportunities and challenges that arouse positive emotions, and provide positive guidance. Their confidence in achieving their mission goals enhances their self-efficacy. At the same time, employees full of self-efficacy will enhance their creativity through creative thinking skills and intrinsic motivation. Consequently, we hypothesize as follows.

Hypothesis 2. Self-efficacy mediates the relationship between challenge stressors and employee creativity.

\subsubsection{Emotional Exhaustion}

As the core dimension of job burnout [30], emotional exhaustion refers to the fatigue caused by excessive use of employees' physiological and emotional resources [31], which is a natural result of the stress coping process [32]. According to Job Demands-Resources Model (JD-R), regardless of the kinds of occupations, job demands can consume the mental energy of employees and lead them to experience job burnout [2]. A relatively balanced state should exist between pressure and resources. When work requirements are increased, employees need to be paid extra compensation to complete the mission objectives. At the same time, higher performance objectives have greater physiological and psychological costs, resulting in increased sympathetic nervous activity, such as fatigue and irritability. Therefore, employees coping with challenge stressors will draw upon their own emotional and cognitive resources and be in a constantly tense state before resources are restored [10]. Long-term 
accumulation will eventually lead to emotional exhaustion. Thus, we argue that challenge stressors positively relate to employees' emotional exhaustion.

Emotional exhaustion is a chronic state of depleted emotional and physiological resources, which in turn leads to a series of reactions such as fatigue, work-related depression, physical and emotional complaints, and anxiety [30]. When individuals feel that the resources invested in their work are not being compensated, they will adopt resource protection strategies to reduce their input of resources [33]. Employees with emotional exhaustion are in a state of depleted cognitive and emotional resources. A loss of cognitive resources causes employees to use simpler cognitive strategies, such as shrinking the focus of their attention. Simple cognitive strategies may lead to more mediocre and less original ideas that are not conducive to the expression of employee creativity [34]. Thus, we argue that emotional exhaustion is negatively associated with employee creativity.

Challenge stressors will result in the loss of employees' cognitive and emotional resources and increase employees' emotional exhaustion. Meanwhile, emotional exhaustion will motivate employees to use resource protection strategies and reduce the investment of energy and resources in work, thus negatively affecting employee creativity. In sum, we posit the following.

Hypothesis 3. Emotional exhaustion suppresses the relationship between challenge stressors and employee creativity.

\subsection{The Moderating Effect of Learning and Relaxation at Work}

\subsubsection{Learning at Work}

According to conservation of resources theory (COR), workplace activities that help individuals gain new resources or prevent resource loss contribute to offsetting pressure [35]. When facing job demands, individuals that construct useful resources actively by resource-building are more likely to evade stress and prevent further resource loss by demand-shielding, which can help recovery [36]. Zhang [18] examined 'learning something new at work' as a resource-building activity and 'taking time for relaxation at work' as a demand-shielding activity. Prior studies have shown that learning and relaxation at work are related to more vitality and less fatigue $[37,38]$.

Employees can learn new things at work in various ways [39]. For example, they may read and print materials online to obtain new information, communicate with colleagues to acquire new skills, or find intellectual challenges in work tasks [40]. When faced with challenge stressors, employees who learn something new at work develop useful resources conducive to solving problems, achieving goals and personal growth, by improving their knowledge, abilities, and skills [41]. This enhances their self-efficacy in coping with work requirements $[13,42]$. On the one hand, learning at work can help employees build the most important resources, such as experience related to work tasks, which helps accomplish mission objectives. On the other hand, sharing experiences with colleagues stimulate vicarious modeling between employees and enhance employees' confidence in overcoming difficulties. The recovery of work resources enhances employees' vitality and arouses positive sentiment towards work [43]. Accordingly, we expect that when individuals learn new things at work, they will be more likely to enhance self-efficacy through building new resources in response to challenge stressors.

Hypothesis 4. Learning something new at work moderates the relationship between challenge stressors and self-efficacy, such that this relationship is stronger at higher levels of learning.

Meanwhile, learning at work cannot only help employees acquire information, knowledge, and experience, but also provide them with psychological and emotional resources [44] and enhance the recovery of energy for work [37]. For example, mastering information search skills can help employees complete their tasks more efficiently, making employees less anxious when faced with time pressure. Reading can expand the horizons of employees and promote the development of an informed mentality, enabling employees to cope with work stress more calmly. According to another 
core content of JD-R, working resources increase the enthusiasm of employees, promote work input, and reduce job burnout [2]. Therefore, in the face of challenge stressors at work, learning new things can provide employees with supplemental work resources and prevent job burnout, thereby relieving employees' emotional exhaustion.

Hypothesis 5. Learning something new at work moderates the relationship between challenge stressors and emotional exhaustion, such that this relationship is weaker at higher levels of learning.

The core view of COR is that individuals with more resources are less susceptible to resource loss and are more capable of obtaining resources. Employees' learning at work can build beneficial resources, offset the threats posed by challenge stressors, and enhance the restoration of work resources. Work resources based on learning promote personal growth and future achievement [45]. Extending this logic one step further, we argue that challenge stressors not only improve employees' self-efficacy, but also relieve emotional exhaustion and stimulate the creativity of employees. As a consequence, we propose moderated mediation models to explore the impact of challenge stressor mechanisms on employee creativity, and the boundaries which trigger these mechanisms into action. Hypothesis 2 and Hypothesis 4 constitute a moderated mediation effect, as do Hypothesis 3 and Hypothesis 5 , that is, self-efficacy and emotional exhaustion convey the impact of challenge stressors on employee creativity and the magnitude of the mediating effect depends on the level of learning.

Hypothesis 6. Learning something new at work moderates the indirect relationship between challenge stressors and employee creativity by self-efficacy, such that this indirect relationship is stronger at higher levels of learning.

Hypothesis 7. Learning something new at work moderates the indirect relationship between challenge stressors and employee creativity by emotional exhaustion, such that this indirect relationship is weaker at higher levels of learning.

\subsubsection{Relaxation at Work}

Relaxation is characterized by a state of low activation and gradual recovery, and relaxation activities require relatively low levels of physical, intellectual, or emotional requirement [44]. Examples of relaxing at work include drinking coffee in the lounge, listening to music, meditating [46], or taking a walk outside [47]. Employees' relaxation at work is essentially a recovery experience [44], and the psychological recovery experience will affect individuals' self-efficacy, which in turn will affect their work behavior [35]. Thus, we propose that, taking time for relaxation at work helps to transform challenge stressors into self-efficacy. For one thing, relaxation tends to increase positive emotions [47]. According to the classification of emotion regulation strategies by Parkinson and Totterdell [48], a relaxation-oriented strategy uses diversion as an emotion regulation strategy, which aims to mitigate negative or tense situations by seeking distraction [44]. Taking time for relaxation at work involves a process of dialogue with oneself, that is, emotional regulation. Active and effective emotional regulation enhances optimistic emotions and promotes self-affirmation [49]. For another thing, relaxation not only prevents unnecessary loss of existing resources, but also provides employees with various resources that can be transferred and utilized, such as focused attention and psychological resilience [17]. Diversified stimuli outside the office space restores individual attention resources in an unconscious and bottom-up way, making room for supplemented top-down and controlled attention resources used at work [18]. Relaxation also promotes the recovery of psychological resources and improves employees' ability to resist stress.

Hypothesis 8. Taking time for relaxation at work moderates the relationship between challenge stressors and self-efficacy, such that this relationship is stronger at higher levels of relaxation. 
Moreover, individuals experience diverse levels of reactivity and resilience to stress [50]. Reactivity refers to a direct physiological and psychological reaction to stressors, and resilience refers to replenishment following resource consumption. Employees respond to job requirements by consuming resources, and challenge stressors involve higher levels of activation [51]. Enthusiasm for achieving work goals encourages employees to invest more time [52], which can have negative consequences if there is no rest for a long period. As a result, cumulative effects such as headache, eyestrain, lumbago, and other physical complaints can arise, and anxiety, fatigue, depression, and other symptoms of emotional burnout [53] will occur naturally. Taking time to relax, such as walking outside, allows employees to temporarily leave a tight working atmosphere, and avoid physical, intellectual, or emotional demands, so that a stressed mood may be relieved, while muscle relaxation and other activities can change the body's long-term working state, permit the body and mind rest, and gradually restore the physiological and emotional system to prestress level [54]. Therefore, relaxation at work will promote employees' recovery of physiological and emotional resources during the stress response process and alleviate emotional exhaustion.

Hypothesis 9. Taking time for relaxation at work moderates the relationship between challenge stressors and emotional exhaustion, such that this relationship is weaker at higher levels of relaxation.

According to COR, employees' relaxation at work in response to challenge stressors can temporarily block work requirements, prevent the further loss of resources, and promote resource recovery. A persistent increase in resources improves employees' social adaptability, which helps to enhance their self-efficacy and stimulate creative behavior [55]. In addition, relaxation activities are related to positive emotions. Positive emotions can eliminate the influence of negative emotions [56]. The positive effects of relaxation help reduce the negative impact of work stress, as well as alleviating employees' emotional exhaustion, by expanding their cognitive, attentional, and behavioral scope, enhancing problem solving skills and their pursuit of creative thinking and behavior [57]. Similarly, Hypothesis 2 and Hypothesis 8 constitute a moderated mediation effect, as do Hypothesis 3 and Hypothesis 9, that is, self-efficacy and emotional exhaustion convey the impact of challenge stressors on employee creativity. The magnitude of the mediating effect depends on the level of relaxation.

Hypothesis 10. Taking time for relaxation at work moderates the indirect relationship between challenge stressors and employee creativity by self-efficacy, such that this indirect relationship is stronger at higher levels of relaxation.

Hypothesis 11. Taking time for relaxation at work moderates the indirect relationship between challenge stressors and employee creativity by emotional exhaustion, such that this indirect relationship is weaker at higher levels of relaxation.

To sum up, this study explored the mechanisms influencing the impact of challenge stressors on employee creativity and the moderating effects of learning and relaxation at work. Figure 1 presents the theoretical model of this study.

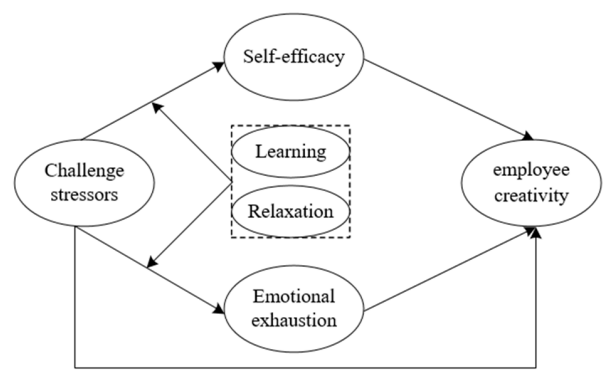

Figure 1. Theoretical model. 


\section{Method}

\subsection{Participants and Procedures}

We administered questionnaires to employees and direct supervisors in two waves, and numbered questionnaires for employees and questionnaires for supervisors to ensure that samples were paired. At time 1, questionnaires for employees were distributed to collect data on challenge stressors, hindrance stressors, self-efficacy, emotional exhaustion, learning, and relaxation. One month after, questionnaires for supervisors were distributed to direct supervisors, who scored the creativity of their subordinates. The samples were recruited from three enterprises in China. The industry areas were information technology, finance and evaluation services.

A total of 343 employees and 59 supervisors were invited to participate in our survey; a supervisor scored several subordinates at the same time in supervisor questionnaire. The paired-samples we retrieved included 276 employees and 51 supervisors. The effective recovery rates of the questionnaires were $80.47 \%$ and $86.44 \%$, respectively. After eliminating invalid questionnaires for serious information loss, inconsistent answers, and regular answers, 240 valid paired questionnaires were obtained, which included 240 employee questionnaires and 47 supervisor questionnaires, with an average of 5.11 employees per supervisor. From the 240 employees participating, $56.67 \%$ were male and $43.33 \%$ were female; the 21-30 years old and 31-40 years old age groups accounted for $40.42 \%$ and $34.17 \%$ of the sample, respectively, leaving $25.41 \%$ outside the $21-40$ age group. Finally, $55.42 \%$ had a master's degree or above; while $61.25 \%$ had been working for five years or less, and the average length time in the organization were 2.43 years.

\subsection{Measures}

The questionnaire collected ratings using a Likert-type scale ranging from 1 ('strongly disagree') to 7 ('strongly agree'). Items related to variables (See Appendix A) were translated into Chinese using the standard translation back-translation procedure [21,58]. Data analysis was performed in five stages, i.e., confirmatory factor analysis (CFA), descriptive statistics, common method biases testing, hypotheses testing, and fuzzy-set qualitative comparative analysis. The analysis was conducted by using Amos version 20, SPSS version 22, and fs-QCA version 3.0 (IBM, Armonk, New York, USA). In hypotheses testing, structural equation modeling was used for the estimation of direct effects and mediating effects of the theoretical model. A hierarchical regression analysis was conducted to test the moderating effects. Finally, we use bootstrapping procedures to perform moderated mediation analyses. In order to reveal the interaction of different antecedents that trigger employee creativity, fuzzy-set qualitative comparative analysis was performed based on the theory of configuration. Table 2 shows the internal consistency reliability scores for each measure, which are described below.

Challenge stressors. We used Cavanaugh's [20] six-item scale to measure challenge stressors. A sample item was 'I have a large number of projects and or assignments'. Cronbach's alpha was 0.88.

Self-efficacy. We used Schwarzer's [59] ten-item self-efficacy scale. A sample item was 'I can always manage to solve difficult problems if I try hard enough'. Cronbach's alpha was 0.93 .

Emotional exhaustion. We used Pugh and Groth's [60] five-item scale to measure emotional exhaustion. A sample item was 'I feel run-down at the end of the workday'. Cronbach's alpha was 0.94 .

Learning and relaxation at work. We used four items adapted from Sonnentag and Fritz's [44] mastery experience scale to measure learning at work. A sample item was 'I spend time learning new things at work'. Cronbach's alpha was 0.88. Four items adapted from Sonnentag and Fritz's [44] relaxation scale were used to measure relaxation at work. A sample item was 'I take time for leisure'. Cronbach's alpha was 0.91 .

Employee creativity. We used Farmer's [61] four-item scale to measure employee creativity. A sample item was 'This employee tries new ideas or methods first'. Cronbach's alpha was 0.89. 
Control variable. As hindrance stressors are another type of job stressors conceptualized in the challenge-hindrance stressors framework, we included hindrance stressors for control purposes. We used Cavanaugh's [20] five-item scale to measure hindrance stressors. A sample item was 'Politics rather than performance has a great influence on organizational decision'. Cronbach's alpha was 0.88 . In addition, gender, age, education level, and working years were also selected as control variables in this study.

\section{Results}

\subsection{Confirmatory Factor Analysis}

We used AMOS 20 to conduct a confirmatory factor analysis of challenge stressors, self-efficacy, emotional exhaustion, learning at work, relaxation at work, and employee creativity, to test the discriminant validity of variables. As shown in Table 1, the model fit of six factors $\left(\chi^{2}=947.463\right.$, $\left.\chi^{2} / \mathrm{df}=2.110, \mathrm{RMSEA}=0.068, \mathrm{CFI}=0.917, \mathrm{TLI}=0.908\right)$ was significantly better than other nested models. In addition, as shown in Table 2, the square roots of average variance extracted (AVE) of the six variables in this study were larger than the absolute values of the correlation coefficients between the various latent variables, indicating that the variables had good discriminant validity.

Table 1. Results of confirmatory factor analysis.

\begin{tabular}{ccccccc}
\hline Models & $\chi^{\mathbf{2}}$ & df & $\chi^{\mathbf{2}} \mathbf{d d f}$ & RMSEA & CFI & TLI \\
\hline six factors & 947.463 & 449 & 2.110 & 0.068 & 0.917 & 0.908 \\
five factors (a) & 1625.934 & 454 & 3.581 & 0.104 & 0.804 & 0.786 \\
five factors (b) & 2019.241 & 454 & 4.448 & 0.120 & 0.738 & 0.714 \\
four factors (c) & 2621.307 & 458 & 5.723 & 0.141 & 0.638 & 0.608 \\
four factors (d) & 2697.642 & 458 & 5.890 & 0.143 & 0.625 & 0.594 \\
three factors(e) & 2988.576 & 461 & 6.483 & 0.151 & 0.577 & 0.545 \\
two factors (f) & 3479.991 & 463 & 7.516 & 0.165 & 0.495 & 0.459 \\
one factor (g) & 3923.689 & 464 & 8.456 & 0.177 & 0.421 & 0.424 \\
\hline
\end{tabular}

Note: Root mean square error of approximation is abbreviated as RMSEA. Comparative fit index is abbreviated as CFI. Tucker-Lewis index is abbreviated as TLI.

Table 2. Descriptive statistics of the variables.

\begin{tabular}{|c|c|c|c|c|c|c|c|c|c|c|c|}
\hline Variables & 1 & 2 & 3 & 4 & 5 & 6 & 7 & 8 & 9 & 10 & 11 \\
\hline 1. Gender & - & & & & & & & & & & \\
\hline 2. Age & -0.051 & - & & & & & & & & & \\
\hline 3. Education level & 0.031 & -0.019 & - & & & & & & & & \\
\hline 4. Working years & $-0.169 * *$ & $0.503 * *$ & $-0.142 *$ & - & & & & & & & \\
\hline 5. Hindrance stressors & 0.000 & -0.028 & $-0.261 * *$ & 0.084 & - & & & & & & \\
\hline 6. Challenge stressors & $-0.140 *$ & $0.157^{*}$ & -0.004 & $0.161 *$ & $0.286^{* *}$ & $(0.783)$ & & & & & \\
\hline 7. Self-efficacy & $-0.113^{\dagger}$ & $0.188^{* *}$ & $0.142 *$ & $0.112^{+}$ & 0.019 & $0.433^{* *}$ & $(0.764)$ & & & & \\
\hline 8. Emotional exhaustion & 0.040 & -0.024 & $-0.132 *$ & -0.049 & $0.387^{* *}$ & $0.352 * *$ & -0.096 & $(0.868)$ & & & \\
\hline 9. Learning & -0.034 & 0.056 & $0.124^{\dagger}$ & 0.030 & 0.002 & $0.397^{* *}$ & $0.603 * *$ & -0.038 & $(0.805)$ & & \\
\hline 10. Relaxation & $0.173^{* *}$ & 0.077 & $0.143 *$ & 0.064 & -0.009 & 0.079 & $0.306^{* *}$ & -0.074 & $0.283^{* *}$ & $(0.859)$ & \\
\hline 11. Employee creativity & -0.051 & $0.117^{\dagger}$ & 0.012 & 0.071 & $0.136^{*}$ & $0.364^{* *}$ & $0.546^{* *}$ & $-0.108^{\dagger}$ & 0.499 ** & $0.159 *$ & $(0.834)$ \\
\hline Mean & 1.533 & 2.246 & 3.146 & 2.433 & 3.809 & 5.024 & 4.723 & 4.150 & 4.844 & 5.214 & 4.263 \\
\hline SD & 0.499 & 0.565 & 0.619 & 0.959 & 1.771 & 1.377 & 1.322 & 1.656 & 1.290 & 1.381 & 1.390 \\
\hline
\end{tabular}

Notes: $\mathrm{N}=240$ employees and 47 supervisors. Internal consistency reliabilities (Square roots of AVE) are reported in parentheses on the diagonal. ${ }^{* *} p<0.01 .{ }^{*} p<0.05 .{ }^{\dagger} p<0.1$.

\subsection{Descriptive Statistics}

Table 2 presents the descriptive statistics and correlations between all variables. As shown in Table 2, challenge stressors positively correlated with self-efficacy $(\mathrm{r}=0.433, p<0.001)$ and emotional exhaustion $(\mathrm{r}=0.352, p<0.001)$, and self-efficacy positively correlated with employee creativity $(\mathrm{r}=0.546, p<0.001)$; however, emotional exhaustion negatively correlated with employee creativity $(\mathrm{r}=-0.108, p<0.1)$. 


\subsection{Common Method Bias Testing}

In order to reduce the influence of common method bias (CMB), we designed the questionnaire for employees and the questionnaire for supervisors, collected paired-sample data from different sources at different time points, and adopted control measures, such as hidden variable names in the questionnaires. To further test for CMB in questionnaire measurement, we adopted the Harman single factor analysis method, using SPSS software and conducting an exploratory factor analysis on all of the variables in our study. The highest variance explained by one factor was $28.719 \%$, which was less than $50 \%$, indicating that $\mathrm{CMB}$ in this study was not significant.

\subsection{Hypotheses Testing}

In this study, we used structural equation modeling to verify the mediating effects. The optimal model was found by comparing a theoretical model, a nested model and an alternative model. Challenge stressors had a direct effect on employee creativity in the theoretical model, while the difference between the nested model and the theoretical model was that the direct effect did not exist in the nested model. The difference between the alternative model and the theoretical model was that there was no mediating effect in alternative model, that is, challenge stressors, self-efficacy, and emotional exhaustion all affected employee creativity directly. First, by comparing the model indexes of the theoretical model and nested model (see Table 3), we found that the fit indexes of the theoretical model and the nested model met the requirements, but the degree of fit of the theoretical model was relatively good. By comparing the chi-square changes of the two models, we found that the chi-squared value had changed significantly $\left(\Delta \chi^{2}=13.064, \Delta \mathrm{df}=1, p<0.05\right)$. Second, the alternative model had a worse fit index than the theoretical model, which meant that the model fit of the alternative model was relatively poor. Following the above analysis, we concluded that the theoretical model was the optimal model for this study.

Table 3. Fit indexes of the theoretical model, nested model, and alternative model.

\begin{tabular}{clcccccc}
\hline & $\chi^{2}$ & df & $\chi^{2} / \mathbf{d f}$ & RMSEA & IFI & TLI & CFI \\
\hline Theoretical model & 776.638 & 363 & 2.139 & 0.069 & 0.916 & 0.905 & 0.915 \\
Nested model & 789.702 & 364 & 2.170 & 0.070 & 0.914 & 0.903 & 0.913 \\
Alternative model & 1103.647 & 373 & 2.959 & 0.091 & 0.851 & 0.837 & 0.850 \\
\hline
\end{tabular}

Note: Incremental fit index is abbreviated as IFI.

Figure 2 shows the path coefficient of the direct effect. Challenge stressors had a direct positive impact on employee creativity ( $\beta=0.352, p<0.001$ ), offering support for Hypothesis 1 . The path coefficients of the theoretical model are shown in Figure 3. Challenge stressors positively related to self-efficacy $(\beta=0.441, p<0.001)$ and emotional exhaustion $(\beta=0.367, p<0.001)$, and self-efficacy ( $\beta=0.426, p<0.001$ ) had a positive effect on employee creativity while emotional exhaustion $(\beta=-0.229, p<0.001)$ and was negatively associated with employee creativity. These results show that the direct effect of challenge stressors on employee creativity was 0.352 . The total indirect effect of challenge stressors on employee creativity was $0.104\left(0.441^{*} 0.426-0.367^{*} 0.229\right)$, with a mediating effect of self-efficacy of $0.188(0.441 * 0.426)$. The mediating effect achieved through emotional exhaustion was $-0.084(-0.367 * 0.229)$. That is, self-efficacy and emotional exhaustion had partial mediating effects on the relationship between challenge stressors and employee creativity. Furthermore, challenge stressors had a positive indirect effect on employee creativity through enhanced self-efficacy, which more than offset the negative indirect effect on employee creativity through increased emotional exhaustion. Hence, Hypotheses 2 and 3 were supported. 


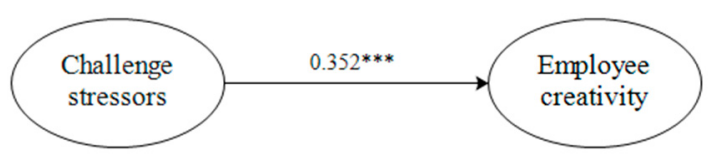

Figure 2. Path coefficient of the direct effect.

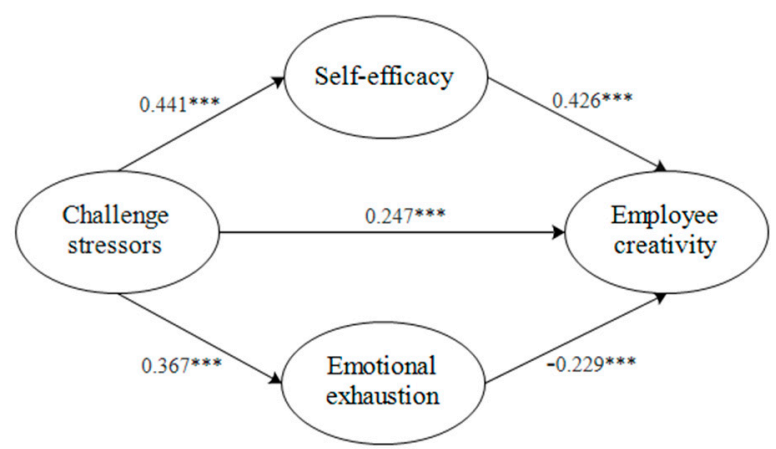

Figure 3. Path coefficients of mediating effects.

In order to test the moderating effects of learning and relaxation, a hierarchical regression analysis was conducted using SPSS 22. The results are shown in Table 4. In support of Hypothesis 4 , the third model in Table 4 shows a significant and positive interaction between challenge stressors and learning at work on self-efficacy $(\beta=0.116, p<0.05)$. However, the interaction between challenge stressors and relaxation at work was not significant $(\beta=-0.007, p>0.1)$, so Hypotheses 8 and 10 were not supported. We did not find support for Hypotheses 5 and 7 either. In the sixth model depicted in Table 4, the interaction between challenge stressors and learning at work on emotional exhaustion was not significant $(\beta=-0.012, p>0.1)$, nor was the interaction between challenge stressors and relaxation at work $(\beta=-0.038, p>0.1)$. That is to say, learning and relaxation at work did not moderate the relationship between challenge stressors and emotional exhaustion, so Hypotheses 9 and 11 were not supported either. To interpret this result, we plotted all the interactions among variables (See Figures 4-7). As shown in Figure 4, challenge stressors had a strong positive relationship with self-efficacy when learning at work was high. Conversely, when learning at work was low, the positive correlation between challenge stressors and self-efficacy was relatively weak.

Table 4. Test of moderative effects.

\begin{tabular}{|c|c|c|c|c|c|c|}
\hline & \multicolumn{3}{|c|}{ Self-Efficacy } & \multicolumn{3}{|c|}{ Emotional Exhaustion } \\
\hline & Model 1 & Model 2 & Model 3 & Model 4 & Model 5 & Model 6 \\
\hline \multicolumn{7}{|l|}{ Control variables } \\
\hline Gender & -0.105 & $-0.092^{\dagger}$ & $-0.090^{\dagger}$ & 0.025 & 0.077 & 0.078 \\
\hline Age & $0.176^{*}$ & 0.117 * & $0.118 *$ & 0.039 & 0.002 & -0.004 \\
\hline Education level & 0.169 * & 0.061 & 0.058 & -0.047 & -0.050 & -0.051 \\
\hline Working years & 0.024 & -0.010 & -0.012 & -0.104 & $-0.119^{\dagger}$ & -0.112 \\
\hline Hindrance stressors & 0.066 & -0.023 & -0.042 & $0.384^{* * *}$ & $0.278^{* * *}$ & $0.281^{* * *}$ \\
\hline \multicolumn{7}{|l|}{ Predictor variables } \\
\hline Challenge stressors & & $0.217^{* * *}$ & $0.235^{* * *}$ & & $0.369 * * *$ & $0.362 * * *$ \\
\hline Learning & & $0.455^{* * *}$ & $0.429^{* * *}$ & & $-0.158^{* *}$ & $-0.158 * *$ \\
\hline Relaxation & & $0.159 * *$ & $0.178^{* * *}$ & & -0.055 & -0.051 \\
\hline \multicolumn{7}{|l|}{ Interactions } \\
\hline Challenge stressors $\times$ Learning & & & $0.116^{*}$ & & & -0.012 \\
\hline Challenge stressors $\times$ Relaxation & & & -0.007 & & & -0.038 \\
\hline $\mathrm{R} 2$ & 0.073 & 0.456 & 0.468 & 0.160 & 0.263 & 0.265 \\
\hline$\Delta \mathrm{R} 2$ & & $0.384^{* * *}$ & $0.012^{+}$ & & $0.103^{* * *}$ & 0.002 \\
\hline $\mathrm{F}$ & $3.677^{* *}$ & $24.253^{* * *}$ & $20.184^{* * *}$ & $8.920^{* * *}$ & $10.295^{* * *}$ & $8.240^{* * *}$ \\
\hline
\end{tabular}

Notes: $\mathrm{N}=240$ employees and 47 supervisors. ${ }^{* * *} p<0.001 .{ }^{* *} p<0.01 .{ }^{*} p<0.05 .{ }^{\dagger} p<0.1$. 


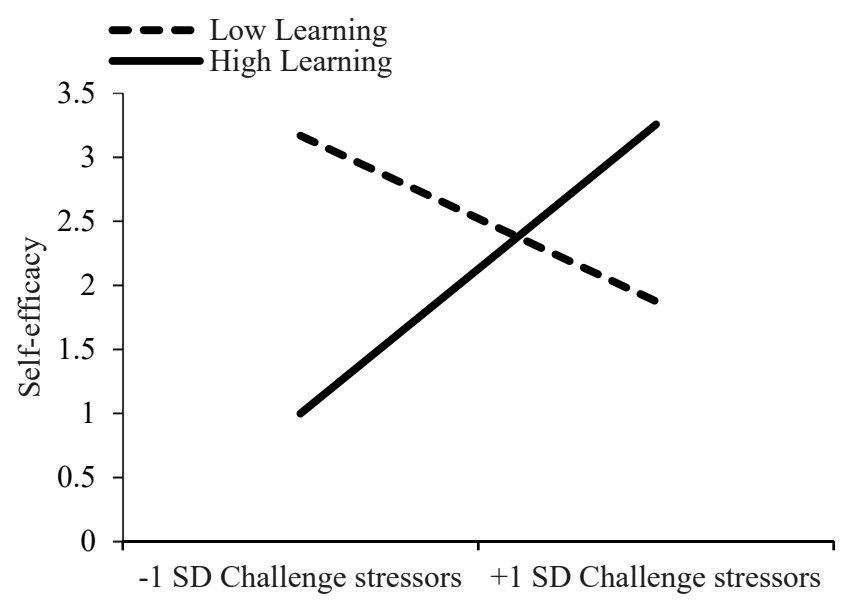

Figure 4. Moderating effect of learning on challenge stressors and self-efficacy.

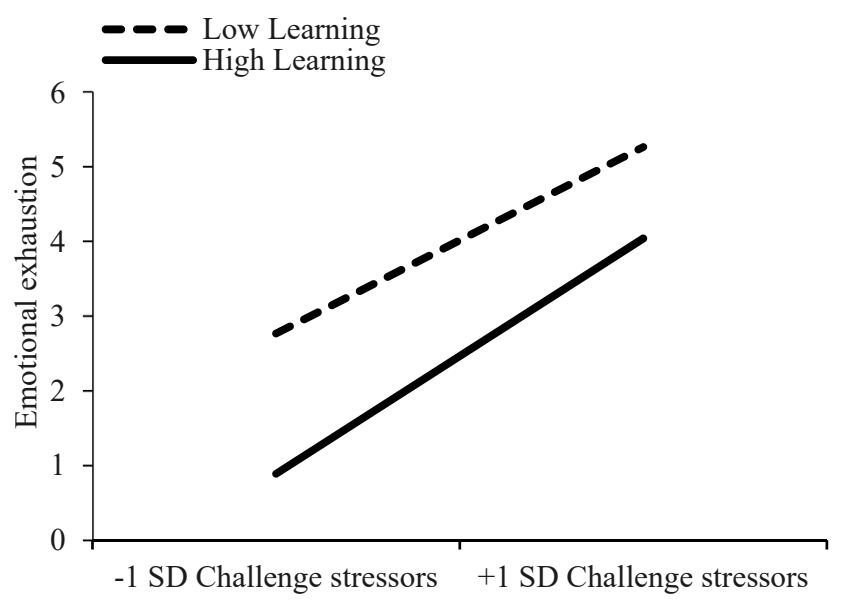

Figure 5. Moderating effect of learning on challenge stressors and emotional exhaustion.

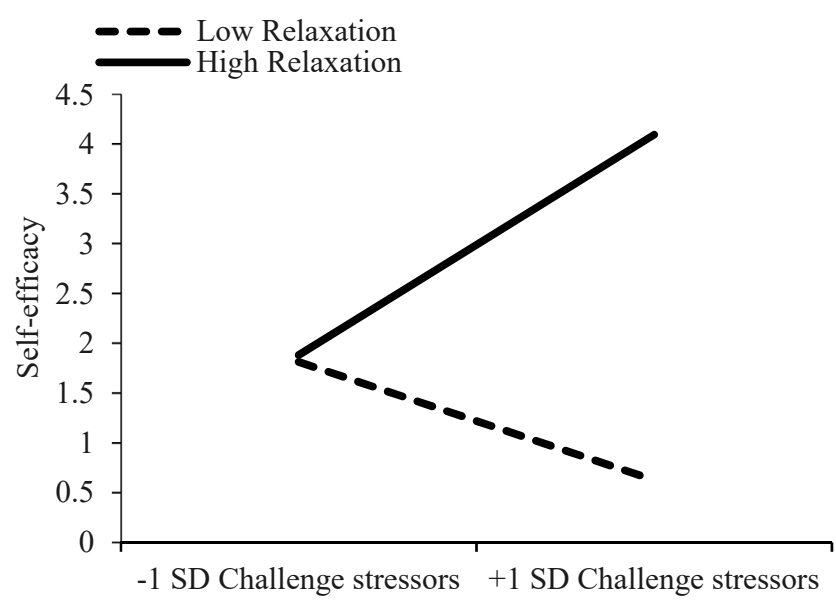

Figure 6. Moderating effect of relaxation on challenge stressors and self-efficacy.

Hypothesis 6 further predicted learning as a moderator of the indirect relationship between challenge stressors and employee creativity mediated by self-efficacy. We tested this hypothesis by performing moderated mediation analyses, using bootstrapping procedures and assessing relationships of interest at high versus low levels (mean +1 SD) of the moderator (Preacher, Rucker, \& Hayes, 2007). As shown in Table 5, the indirect effect of challenge stressors on employee creativity via self-efficacy was significant at a high level of learning $(\beta=0.083, p<0.001)$ but not at a low level of learning 
( $\beta=0.021, p>0.05)$, and the $95 \%$ confidence interval showed that this difference was significant $(\beta=0.062, p<0.001)$. These results supported Hypothesis 6 .

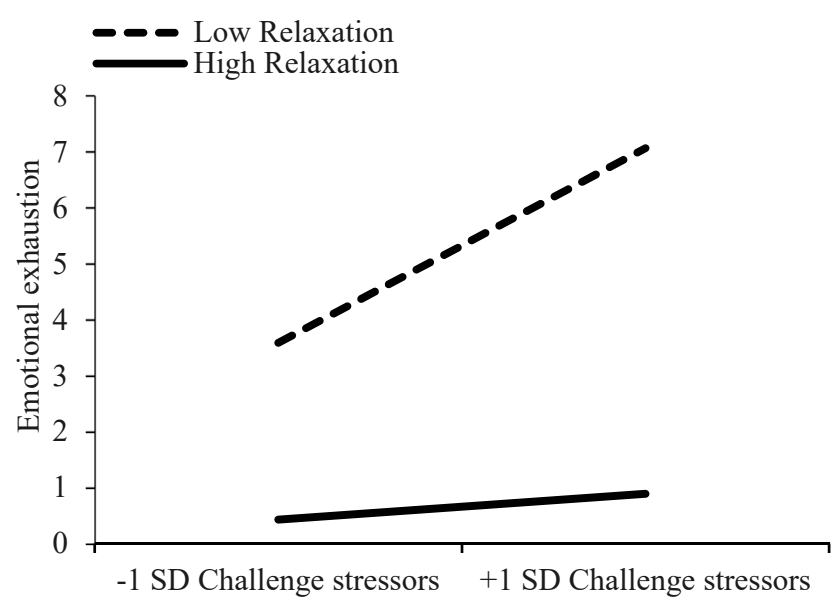

Figure 7. Moderating effect of relaxation on challenge stressors and emotional exhaustion.

Table 5. Analysis of moderated mediation effect (self-efficacy as a mediator).

\begin{tabular}{ccc}
\hline \multirow{2}{*}{ Moderator } & \multicolumn{2}{c}{ Challenge Stressors $(\mathbf{X}) \rightarrow$ Self-Efficacy $(\mathbf{M}) \rightarrow$ Employee Creativity $(\mathbf{Y})$} \\
\cline { 2 - 3 } & Indirect Effect & $\mathbf{9 5 \% \mathbf { C I }}$ \\
\hline High learning & $0.083^{* * *}$ & {$[0.043,0.145]$} \\
Low learning & 0.021 & {$[-0.013,0.065]$} \\
Difference & $0.062^{* * *}$ & {$[0.033,0.116]$} \\
\hline
\end{tabular}

Note: Confidence interval is abbreviated as CI. ${ }^{* * *} p<0.001$.

\section{Fuzzy-Set Qualitative Comparative Analysis}

The promotion of employee creativity is a complex process, which is the result of the interaction of multiple factors such as working environment, working resources, and individual characteristics. This requires us to use a holistic perspective to analyze the key elements of employee creativity from interaction of multiple antecedents. Configuration analysis is based on the assumption that variables are interdependent, focusing on how the combination of variables works at the configuration level [62]. Multiple conjunctural causation, equifinality, and asymmetry are important characteristics of fuzzy-set qualitative comparative analysis (fsQCA), which is rooted in configuration theory. On the basis of quantitative research, this study used the advantages of QCA to integrate six preexisting conditions of challenge stressors, hindrance stressors, self-efficacy, emotional exhaustion, learning, and relaxation. The key was to reveal the combination mode of antecedents that trigger employee creativity. By analyzing how different antecedents work together on equivalent path of employee creativity, the conclusions drawn from quantitative research were further extended.

\subsection{Selection and Calibration of Variables}

Based on theoretical and empirical research findings supporting for the relationship between challenge stressors, hindrance stressors, self-efficacy, emotional exhaustion, learning, relaxation, and employee creativity, this study chose six variables as antecedent conditions and took their average. According to the direct calibration method proposed by Ragin [63], the values of membership degree of 5\% (fully out), 50\% (crossover point), and 95\% (fully in) were calibrated. This study examined whether each antecedent condition was a sufficient and/or necessary condition for the outcome variable. From the perspective of adequacy, the consistency rate of antecedent factors affecting employee creativity, except for challenge stressors, self-efficacy, learning, and relaxation, did not reach the standard level of 0.9 [64], that is, these factors did not constitute sufficient conditions. From the 
perspective of necessity, the coverage rate of antecedent factors did not exceed 0.9 , nor was it a necessary condition to enhance employee creativity. Results showed that we needed to combine antecedent conditions to perform a configuration analysis.

\subsection{Configurations for Employee Creativity}

The results of the configuration analysis in Table 6, showed there were three different paths that enhanced employee creativity, namely C1, C2, and C3, which embodied the characteristic of 'equifinality'. The overall solution consistency was 0.924 , greater than the threshold of 0.8 , and the overall solution coverage was 0.699 .

Table 6. Configurations for employee creativity.

\begin{tabular}{|c|c|c|c|}
\hline \multirow{2}{*}{ Configuration } & \multicolumn{3}{|c|}{ Employee Creativity } \\
\hline & $\mathrm{C} 1$ & $\mathrm{C} 2$ & C3 \\
\hline Challenge stressors & $\bullet$ & $\bullet$ & $\bullet$ \\
\hline Hindrance stressors & & & 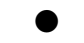 \\
\hline Self-efficacy & $\bullet$ & $\bullet$ & $\bullet$ \\
\hline Emotional exhaustion & $\bullet$ & $\otimes$ & $\bullet$ \\
\hline Learning at work & - & ○ & $\otimes$ \\
\hline Relaxation at work & $\otimes$ & $\bullet$ & $\bullet$ \\
\hline Consistency & 0.946 & 0.947 & 0.956 \\
\hline Raw coverage & 0.350 & 0.596 & 0.373 \\
\hline Unique coverage & 0.044 & 0.256 & 0.034 \\
\hline Overall solution consistency & & 0.924 & \\
\hline Overall solution coverage & & 0.699 & \\
\hline
\end{tabular}

Notes: Condition is present $=\bullet$ or $\bullet$; Condition is absent $=\otimes$ or $\otimes$; Condition is present or absent $=$ 'blank'; Condition is core $=\boldsymbol{0}$ or $\otimes$; Condition is noncore $=\bullet$ or $\otimes$.

Configuration 1 lacked the core condition of relaxation at work, and coexisted with challenge stressors, self-efficacy, emotional exhaustion and learning at work as present noncore conditions. Specifically, challenge stressors have a 'double-edged sword' effect $[2,65]$. Based on the individuals' cognition of stress and job requirements within their own abilities, and the individuals' growing demands for job challenges and opportunities, challenge stressors may enhance self-efficacy. At the same time, high performance standard and strict requirements of work tasks can lead to the loss of individuals' cognitive and psychological resources. In response to the empirical findings of this study, relaxation at work has no substantial effect on relieving emotional exhaustion and improving self-efficacy. Therefore, relaxation at work cannot be sufficient. That is, relaxation at work cannot serve as a buffer to challenge stressors or as a booster of innovative behavior. However, in the absence of relaxation activities, the positive influence of knowledge acquisition due to challenge stressors on individual self-efficacy helps to further stimulate creativity at work. Ultimately, superimposed effect offsets the negative impact of emotional exhaustion, and promotes the development of employee creativity.

Configuration 2 was characterized by challenge stressors and learning at work as present core conditions, emotional exhaustion as the absent core condition, and self-efficacy and relaxation at work as noncore conditions. Prior studies have pointed out challenge stressors are important situational factors that stimulate employee creativity, and it is very important to understand what kinds of circumstances can maximize their positive impact [66]. According to COR, learning at work as a resource-building activity can make up for the work resources that employees lose when responding to work requirements. Actively seeking new resources helps employees cope with the threats posed by challenge stressors. Moreover, learning stimulates positive emotions and motivation and promotes employee innovation at work. At the same time, employees who have strong confidence in their ability to accomplish their mission goals in the work situation despite challenge stressors, will often experience 
higher intrinsic motivation and self-expectation, and tend to focus more on creative activities that replenish work resources, such as learning at work and appropriate relaxation. This enables such employees to avoid emotional exhaustion and creatively respond to complex work tasks.

Configuration 3 coexisted with hindrance stressors as the present core condition, learning at work as the absent core condition, and challenge stressors, self-efficacy, emotional exhaustion, and relaxation at work as noncore conditions. When challenge stressors exist and hindrance stressors are as the dominant stress factors, according to the theory of learning under stress [27], employees perceive organizational politics, role ambiguity, red rale, and other situations that are not related to the task itself, as beyond the scope of their capabilities. Under these circumstances, they are much more likely to experience exhaustion and anxiety, and have a low motivation to learn. Navigating the gaps in the system leads to the physical and mental exhaustion of employees, and reduces the level of energy required to perform cognitive tasks related to learning. Even if it is barely learning, it is difficult to focus their available cognitive resources on the task. On the contrary, learning will further aggravate individuals' emotional exhaustion, and it is not conducive to the exertion of creativity. Relaxation at work cannot only restore individual physiological resources, but also avoid further loss of psychological and cognitive resources [67]. Therefore, in situations where hindrance stressors predominate, individuals will avoid learning activities to prevent the exacerbation of physical and mental exhaustion. Conversely, relaxation can help employees avoid excessive work demands and alleviate emotional exhaustion, enhance recovery after long-term working status, support employees' positive emotional adjustment, and improve self-efficacy. Furthermore, after relaxation activities, employees become more focused and flexible in solving problems, and are more likely to pursue creative thinking and behavior.

\section{Discussion}

\subsection{General Discussion}

On the basis of quantitative research and qualitative comparative analysis conducted above, we drew the following conclusions:

First, challenge stressors have a positive direct impact on employee creativity; meanwhile, self-efficacy and emotional exhaustion partially mediate the relationship between challenge stressors and employee creativity. On the one hand, challenge stressors stimulate the development of employees' self-efficacy and further inspire their innovative ideas and behaviors at work; on the other hand, they can emotionally exhaust employees, which adversely affects their creativity. These two kinds of effects exist at the same time, there is no prior relationship, and they are not simple opposites.

Second, learning at work moderates the mediating role of self-efficacy. Learning activities under challenge stressors, such as acquiring new knowledge and skills, can make up for the loss of working resources, further enhance employees' beliefs and confidence in their ability to fulfil their mission objectives, and benefit employees' capacity for innovation. However, learning cannot alleviate the emotional exhaustion of employees in response to challenge stressors. When employees face heavy job demands, tight time schedules, and extensive responsibilities, they are often placed in a fast-paced work environment to pursue rewards such as a salary increase, promotion, or organizational trust. Enthusiasm for work will encourage employees to continuously acquire new knowledge and skills related to their work, and improve their work efficiency. However, if the employees in a high-stress situation cannot switch between work and rest in a timely manner, their physical and psychological resources will be continuously consumed. Not only will work efficiency not improve, but emotional exhaustion will worsen and become 'the straw that broke the camel's back'. It is worth noting that relaxation at work does not increase the self-efficacy of employees' coping with challenge stressors, nor does it alleviate the emotional exhaustion caused by challenge stressors. The potential reasons why relaxation activities have not significant effect may lie in some of their limitations [18]. Relaxing at work by itself does not help individuals cope effectively with stressful situations. When individuals 
finish relaxing at work and realize that the time spent has failed to change their high work load, it may exacerbate tension and frustration, thereby diluting the recovery function of relaxation. Moreover, inappropriate relaxation at work will also weaken its positive impact. In many cases, employees relax by binge-watching and playing games to temporarily escape from pressure, which only consumes time and interrupts a consistent working state. As a result, their concentration on work tasks may deteriorate after a short rest, and this is more likely to aggravate the depletion of psychological and emotional resources.

Third, the results of qualitative comparative analysis show that there are three types of configuration that can stimulate employee creativity. Configuration 1 comprised a combination of challenge stressors, self-efficacy, emotional exhaustion, learning, and no relaxation at work. Configuration 2 comprised challenge stressors, self-efficacy, no emotional exhaustion, learning, and relaxation at work. Configuration 3 combined challenge stressors, hindrance stressors, self-efficacy, emotional exhaustion, relaxation, and no learning at work. The unique coverage of configuration 2 exceeded the sum of the unique coverage of the other two configurations $(0.256>0.044 / 0.034)$. Configuration 1 validates the conclusion of quantitative research that learning under challenge stressors are beneficial to employee creativity, while relaxation has no significant effect. Nevertheless, in configuration 3, learning at work needs to be avoided when hindrance stressors dominate, and relaxation activities can buffer the negative impact of hindrance stressors, which enhances employees' capacities for open and divergent thinking. Moreover, on the basis of quantitative research, qualitative comparative analysis included hindrance stressors as a precondition, which is a further enrichment and extension of quantitative research results. Finally, configuration 1 further verifies the quantitative research result that self-efficacy and emotional exhaustion coexist in the situation of challenge stressors. Self-efficacy exists in configurations 1, 2, and 3 (the sum of unique coverage was $0.044+0.256+0.034$ $=0.334$ ), while emotional exhaustion is present in configurations 1 and 3 (the sum of unique coverage was $0.044+0.034=0.078$ ), in other words, from the perspective of sample size, it can be concluded that employees under challenge stressors are more likely to enhance creativity through the promotion mechanism of self-efficacy.

\subsection{Theoretical Implications}

Our research makes several important theoretical contributions. First, it has clarified the relationship between challenge stressors and employee creativity. Previous studies have drawn inconsistent conclusions about the relationship between challenge stressors and employee creativity, including a positive relationship [68], a moderated positive relationship [7], a moderated negative relationship [6], and a curvilinear relationship [69]. However, rarely have studies examined the double-edged effect of challenge stressors [2]. In this study, we explored the promotion and depletion mechanisms of self-efficacy and emotional exhaustion, to deepen our understanding of the double-edged effect of challenge stressors on employee creativity, and enrich the previous literatures on the relationship between challenge stressors and employee creativity.

Second, according to COR, we explored the moderating effect of learning and relaxation on the promotion and depletion mechanisms of challenge stressors, from the perspective of individual initiative. Prior studies on the boundary conditions of challenge stressors and employee creativity focused on organizational and leadership factors, such as organizational support, superior-subordinate relationships, and leadership styles. However, these studies lacked insight into the actions individuals may take to manage their work. Considering the internal factors of employees, we regarded 'learning at work' as a resource-building activity, and 'relaxation at work' as a demand-shielding activity, and explored learning and relaxation at work as the boundaries of intrinsic mechanisms mediating challenge stressors and employee creativity. Thus, a new perspective on individual behavior orientation at work was the focus of this study. In addition, our quantitative study has shown that learning can enhance the self-efficacy of employees facing challenge stressors, and relaxation has no significant 
effect, which expands the boundaries of the internal mechanisms mediating the effect of challenge stressors on employee creativity.

Third, the quantitative method was combined with qualitative comparative analysis to further probe how employee creativity is activated from the perspective of configuration. The quantitative method confirmed the causal relationships between variables through the study of several factors affecting employees creativity, but it was confined to the analysis of the net effect of each variable, and was unable to handle the complex relationship between more than three antecedents [19]. Employee creativity is the result of an interaction between multiple factors. Qualitative comparative analysis incorporates multiple antecedent conditions, revealing the combined effects of antecedent factors that trigger employee creativity. Based on the advantages of qualitative comparative analysis, we analyzed three configurations of how different factors work together on employee creativity, and further extended the results of the quantitative research. This confirmed the complexity and diversity of the employee creativity development path. At the same time, this study responded to Whittington's [70] advocacy for the application of QCA to organizational behavior research.

\subsection{Practical Implications}

First, appropriate challenge stressors levels should be maintained to motivate employees and provide them with the necessary support. At the same time, managers should focus on improving employees' self-efficacy and alleviating their emotional exhaustion at work. Second, managers should pay attention to the role of employees' internal factors in enhancing their creativity. Managers can provide opportunities for employees to learn new things at work or to promote self-learning while they work. Similarly, employees who want to complete their work tasks creatively can also seek ways to learn new things consciously during their daily work. Finally, relaxation may not always be as useful as people sometimes think. It should be tailored to the time, place and person. Although relaxation can be good for health and be fatigue-reducing [38], learning at work for resource-building is often a wise choice when facing challenge stressors.

The promotion of employees' creativity and improvement of their working status depend on the interrelationship and interaction of various factors, including the specific situation, organization, and individual. Managers should abandon atomic and linear thinking, and conduct in-depth analysis of various elements and their links, to determine how they affect employees' creativity from a holistic perspective. Identifying critical endogenous factors that restrict employee creativity in a specific enterprise or organizational department is necessary to design solutions based on these factors. For example, employees should be encouraged to learn more and acquire effective work resources to enhance their innovation ability when facing challenge stressors, such as tight time schedules, heavy tasks, enormous responsibilities, and a wide range of activities. When employees are in a situation dominated by hindrance stressors, they should avoid continuous learning and working states to prevent the persistent consumption of physiological and emotional resources. On the contrary, they should adjust themselves according to the principle of 'work and rest' and maintain their best state at work, to promote the burst of creativity.

\subsection{Limitations and Future Directions}

There were some limitations to this study. One was the use of general items to measure learning and relaxation, without referring to more specific behaviors such as reading online materials, listening to music, etc. Different definitions of learning and relaxation activities may lead to differences and inaccuracies in the assessment of learning and relaxation at work. Second, the antecedent conditions for improving employee creativity are diverse, but this study was limited to exploring the combined effects of six factors only.

Future studies may consider using measures that refer to more specific learning and relaxation behaviors at work and explore the impact of emotions at an individual level, corporate culture at the organizational level, and other factors that impact upon employee creativity. This would open the 
black box of employee creativity to a more comprehensive perspective. Researchers could also explore the potential mechanisms of additional forms of resource-building and demand-shielding activities on employee creativity or other dependent variables.

Author Contributions: X.H. contributed to study design, data collection, and drafting and revising the manuscript. Y.S. conceptualized the research design, reviewed the manuscript, and collected and sorted some of the data. Y.D. contributed to writing and interpretation of the findings. All authors read, revised, and approved the final manuscript.

Funding: This research was supported by the National Social Science Fund of China (Grant number 18BGL083) and Beijing Natural Science Foundation of China (Grant number 9172007).

Conflicts of Interest: The authors declare no conflicts of interest.

\section{Appendix A}

Table A1. Research constructs and measurements.

\begin{tabular}{|c|c|}
\hline Items & Factor Loading \\
\hline \multicolumn{2}{|l|}{ Challenge stressors } \\
\hline The number of projects and or assignments I have. & 0.791 \\
\hline The amount of time I spend at work. & 0.863 \\
\hline The volume of work that must be accomplished in the allotted time. & 0.841 \\
\hline Time pressures I experience. & 0.796 \\
\hline The amount of responsibility I have. & 0.593 \\
\hline The scope of responsibility my position entails. & 0.432 \\
\hline \multicolumn{2}{|l|}{ Hindrance Stressors } \\
\hline The degree to which politics rather than performance affects organizational decisions. & 0.512 \\
\hline The inability to clearly understand what is expected of me on the job. & 0.617 \\
\hline The amount of red tape I need to go through to get my job done. & 0.600 \\
\hline The lack of job security I have. & 0.580 \\
\hline The degree to which my career seems "stalled". & 0.539 \\
\hline \multicolumn{2}{|l|}{ Self-efficacy } \\
\hline I can always manage to solve difficult problems if I try hard enough. & 0.668 \\
\hline If someone opposes me. I can find means and ways to get what I want. & 0.585 \\
\hline It is easy for me to stick to my aims and accomplish my goals. & 0.525 \\
\hline I am confident that I could deal efficiently with unexpected events. & 0.763 \\
\hline Thanks to my resourcefulness, I know how to handle unforeseen situations. & 0.811 \\
\hline I can solve most problems if I invest the necessary effort. & 0.728 \\
\hline I can remain calm when facing difficulties because I can rely on my coping abilities. & 0.853 \\
\hline When I am confronted with a problem, I can usually find several solutions. & 0.918 \\
\hline If I am in a bind, 1 can usually think of something to do. & 0.903 \\
\hline No matter what comes my way, I'm usually able to handle it. & 0.786 \\
\hline \multicolumn{2}{|l|}{ Emotional exhaustion } \\
\hline Being tired. & 0.888 \\
\hline Being "wiped out". & 0.894 \\
\hline Feeling run-down. & 0.858 \\
\hline Feeling rejected. & 0.868 \\
\hline Being exhausted. & 0.829 \\
\hline \multicolumn{2}{|l|}{ Learning at work } \\
\hline I spend time learning new things at work & 0.738 \\
\hline I seek out intellectual challenges at work. & 0.858 \\
\hline I do things that challenge me at work. & 0.776 \\
\hline I use part of the work time to do things that broaden my horizons. & 0.841 \\
\hline \multicolumn{2}{|l|}{ Relaxation at work } \\
\hline I kick back and relax. & 0.737 \\
\hline I do relaxing things. & 0.905 \\
\hline I use some time to relax. & 0.958 \\
\hline I take time for leisure. & 0.820 \\
\hline \multicolumn{2}{|l|}{ Employee creativity } \\
\hline This employee tries new ideas or methods first. & 0.913 \\
\hline This employee seeks new ideas and ways to solve problems. & 0.923 \\
\hline This employee generates ground-breaking ideas related to the field. & 0.851 \\
\hline This employee is a good role model for creativity. & 0.608 \\
\hline
\end{tabular}




\section{References}

1. Allen, M.T.; Bocek, C.M.; Burch, A.E. Gender differences and the relationships of perceived background stress and psychological distress with cardiovascular responses to laboratory stressors. Int. J. Psychophysiol. 2011, 81, 209-217. [CrossRef] [PubMed]

2. Widmer, P.S.; Semmer, N.K.; Kälin, W.; Jacobshagen, N.; Meier, L.L. The ambivalence of challenge stressors: Time pressure associated with both negative and positive well-being. J. Vocat. Behav. 2012, 80, 422-433. [CrossRef]

3. Tadić, M.; Bakker, A.B.; Oerlemans, W.G.M. Challenge versus hindrance job demands and well-being: A diary study on the moderating role of job resources. J. Occup. Organ. Psychol. 2015, 88, 702-725. [CrossRef]

4. Fu, N.; Bosak, J.; Flood, P.C.; Ma, Q. Chinese and Irish professional service firms compared: Linking HPWS, organizational coordination, and firm performance. J. Bus. Res. 2019, 95, 266-276. [CrossRef]

5. Zheng, X.; Li, N.; Brad Harris, T.; Liao, H. Unspoken yet understood: An introduction and initial framework of subordinates' Moqi with supervisors. J. Manag. 2019, 45, 955-983. [CrossRef]

6. Sacramento, C.A.; Fay, D.; West, M.A. Workplace duties or opportunities? Challenge stressors, regulatory focus, and creativity. Organ. Behav. Hum. Decis. Process. 2013, 121, 141-157. [CrossRef]

7. Zhang, Y.; LePine, J.A.; Buckman, B.R.; Wei, F. It's Not Fair ... Or is it? The role of justice and leadership in explaining work stressor-Job performance relationships. Acad. Manag. J. 2014, 57, 675-697. [CrossRef]

8. Zhang, X.; Zhou, J.; Kwan, H.K. Configuring challenge and hindrance contexts for introversion and creativity: Joint effects of task complexity and guanxi management. Organ. Behav. Hum. Decis. Process. 2017, 143, 54-68. [CrossRef]

9. Prem, R.; Ohly, S.; Kubicek, B.; Korunka, C. Thriving on challenge stressors? Exploring time pressure and learning demands as antecedents of thriving at work. J. Organ. Behav. 2017, 38, 108-123. [CrossRef]

10. Podsakoff, N.P.; Lepine, J.A.; Lepine, M.A. Differential challenge stressor-hindrance stressor relationships with job attitudes, turnover intentions, turnover, and withdrawal behavior: A meta-analysis. J. Appl. Psychol. 2007, 92, 438. [CrossRef]

11. Lin, W.; Ma, J.; Wang, L.; Wang, M. A double-edged sword: The moderating role of conscientiousness in the relationships between work stressors, psychological strain, and job performance. J. Organ. Behav. 2015, 36, 94-111. [CrossRef]

12. Staufenbiel, T.; König, C.J. A model for the effects of job insecurity on performance, turnover intention, and absenteeism. J. Occup. Organ. Psychol. 2010, 83, 101-117. [CrossRef]

13. Bandura, A. Social cognitive theory: An agentic perspective. Annu. Rev. Psychol. 2001, 52, 1-26. [CrossRef]

14. Wallace, J.C.; Edwards, B.D.; Arnold, T.; Frazier, M.L.; Finch, D.M. Work stressors, role-based performance, and the moderating influence of organizational support. J. Appl. Psychol. 2009, 94, 254-262. [CrossRef]

15. Buch, R.; Dysvik, A.; Kuvaas, B.; Nerstad, C.G.L. It takes three to tango: Exploring the interplay among training intensity, job autonomy, and supervisor support in predicting knowledge sharing. Hum. Resour. Manag. 2015, 54, 623-635. [CrossRef]

16. Trougakos, J.P.; Beal, D.J.; Green, S.G.; Weiss, H.M. Making the break count: An episodic examination of recovery activities, emotional experiences, and positive affective displays. Acad. Manag. J. 2008, 51, 131-146. [CrossRef]

17. Hunter, E.M.; Wu, C. Give me a better break: Choosing workday break activities to maximize resource recovery. J. Appl. Psychol. 2016, 101, 302-311. [CrossRef]

18. Zhang, C.; Mayer, D.M.; Hwang, E. More is less: Learning but not relaxing buffers deviance under job stressors. J. Appl. Psychol. 2018, 103, 123-136. [CrossRef]

19. Woodside, A.G. Moving beyond multiple regression analysis to algorithms: Calling for adoption of a paradigm shift from symmetric to asymmetric thinking in data analysis and crafting theory. J. Bus. Res. 2013, 66, 463-472. [CrossRef]

20. Cavanaugh, M.A.; Boswell, W.R.; Roehling, M.V.; Boudreau, J.W. An empirical examination of self-reported work stress among U.S. managers. J. Appl. Psychol. 2000, 85, 65-74. [CrossRef]

21. Lin, B.; Law, K.S.; Zhou, J. Why is Underemployment related to creativity and OCB? A task-crafting explanation of the curvilinear moderated relations. Acad. Manag. J. 2017, 60, 156-177. [CrossRef]

22. Lazarus, R.S.; Folkman, S. Stress: Appraisal and Coping; Springer: New York, NY, USA, 1984; 456p. 
23. Edwards, J.R.; Cooper, C.L. The person-environment fit approach to stress: Recurring problems and some suggested solutions. J. Organ. Behav. 1990, 11, 293-307. [CrossRef]

24. Janssen, O. Job demands, perceptions of effort-reward fairness and innovative work behaviour. J. Occup. Organ. Psychol. 2000, 73, 287-302. [CrossRef]

25. Lazarus, R.S. Psychological stress in the workplace. J. UOEH 1989, 11, 528-540.

26. Walumbwa, F.O.; Christensen-Salem, A.; Hsu, I.C.; Misati, E. Creative Self-Efficacy and Creative Performance: Understanding the Underlying Mechanisms; Academy of Management Briarcliff Manor: Briarcliff Manor, NY, USA, 2018; 10208p.

27. Lepine, J.A.; Lepine, M.A.; Jackson, C.L. Challenge and hindrance stress: Relationships with exhaustion, motivation to learn, and learning performance. J. Appl. Psychol. 2004, 89, 883-891. [CrossRef]

28. Amabile, T.M. Motivating creativity in organizations: On doing what you love and loving what you do. Calif. Manag. Rev. 1997, 40, 39-58. [CrossRef]

29. Baas, M.; De Dreu, C.K.W.; Nijstad, B.A. A meta-analysis of 25 years of mood-creativity research: Hedonic tone, activation, or regulatory focus? Psychol. Bull. 2008, 134, 779-806. [CrossRef]

30. Cropanzano, R.; Rupp, D.E.; Byrne, Z.S. The relationship of emotional exhaustion to work attitudes, job performance, and organizational citizenship behaviors. J. Appl. Psychol. 2003, 88, 160-169. [CrossRef]

31. Maslach, C.; Schaufeli, W.B.; Leiter, M.P. Job burnout. Annu. Rev. Psychol. 2001, 52, 397-422. [CrossRef]

32. Costa, S.P.; Neves, P. Forgiving is good for health and performance: How forgiveness helps individuals cope with the psychological contract breach. J. Vocat. Behav. 2017, 100, 124-136. [CrossRef]

33. Hobfoll, S.E. The influence of culture, community, and the nested-self in the stress process: Advancing conservation of resources theory. Appl. Psychol. 2001, 50, 337-369. [CrossRef]

34. Byron, K.; Khazanchi, S.; Nazarian, D. The relationship between stressors and creativity: A meta-analysis examining competing theoretical models. J. Appl. Psychol. 2010, 95, 201-212. [CrossRef]

35. Halbesleben, J.R.B.; Neveu, J.-P.; Paustian-Underdahl, S.C.; Westman, M. Getting to the "COR": Understanding the role of resources in conservation of resources theory. J. Manag. 2014, 40, 1334-1364. [CrossRef]

36. Sonnentag, S.; Mojza, E.J.; Demerouti, E.; Bakker, A.B. Reciprocal relations between recovery and work engagement: The moderating role of job stressors. J. Appl. Psychol. 2012, 97, 842-853. [CrossRef]

37. Fritz, C.; Lam, C.F.; Spreitzer, G.M. It's the little things that matter: An examination of knowledge workers' energy management. Acad. Manag. Perspect. 2011, 25, 28-39.

38. Trougakos, J.P.; Hideg, I.; Cheng, B.H.; Beal, D.J. Lunch breaks unpacked: The role of autonomy as a moderator of recovery during lunch. Acad. Manag. J. 2014, 57, 405-421. [CrossRef]

39. Noe, R.A.; Clarke, A.D.M.; Klein, H.J. Learning in the twenty-first-century workplace. Annu. Rev. Organ. Psychol. Organ. Behav. 2014, 1, 245-275. [CrossRef]

40. Doornbos, A.J.; Simons, R.-J.; Denessen, E. Relations between characteristics of workplace practices and types of informal work-related learning: A survey study among Dutch police. Hum. Resour. Dev. Q. 2008, 19, 129-151. [CrossRef]

41. Ployhart, R.E.; Moliterno, T.P. Emergence of the human capital resource: A multilevel model. Acad. Manag. Rev. 2011, 36, 127-150. [CrossRef]

42. Frayne, C.A.; Geringer, J.M. Self-management training for improving job performance: A field experiment involving salespeople. J. Appl. Psychol. 2000, 85, 361-372. [CrossRef]

43. Bakker, A.B.; Demerouti, E.; Brummelhuis, L.L.T. Work engagement, performance, and active learning: The role of conscientiousness. J. Vocat. Behav. 2012, 80, 555-564. [CrossRef]

44. Sonnentag, S.; Fritz, C. The recovery experience questionnaire: Development and validation of a measure for assessing recuperation and unwinding from work. J. Occup. Health Psychol. 2007, 12, 204-221. [CrossRef]

45. Sonenshein, S.; Dutton, J.E.; Grant, A.M.; Spreitzer, G.M.; Sutcliffe, K.M. Growing at work: Employees' interpretations of progressive self-change in organizations. Organ. Sci. 2013, 24, 552-570. [CrossRef]

46. Grossman, P.; Niemann, L.; Schmidt, S.; Walach, H. Mindfulness-based stress reduction and health benefits. J. Psychosom. Res. 2004, 57, 35-43. [CrossRef]

47. Stone, A.A.; Kennedy-Moore; Eileen Neale, J.M. Association between daily coping and end-of-day mood. Health Psychol. 1995, 14, 341-349. [CrossRef] [PubMed]

48. Parkinson, B.; Totterdell, P. Classifying affect-regulation strategies. Cogn. Emot. 1999, 13, 277-303. [CrossRef] 
49. Humphrey, R.H.; Ashforth, B.E.; Diefendorff, J.M. The bright side of emotional labor. J. Organ. Behav. 2015, 36, 749-769. [CrossRef]

50. Linden, W.; Earle, T.L.; Gerin, W.; Christenfeld, N. Physiological stress reactivity and recovery: Conceptual siblings separated at birth? J. Psychosom. Res. 1997, 42, 117-135. [CrossRef]

51. Brosschot, J.F.; Pieper, S.; Thayer, J.F. Expanding stress theory: Prolonged activation and perseverative cognition. Psychoneuroendocrinology 2005, 30, 1043-1049. [CrossRef] [PubMed]

52. Wood, S.J.; Michaelides, G. Challenge and hindrance stressors and wellbeing-based work-nonwork interference: A diary study of portfolio workers. Hum. Relat. 2016, 69, 111-138. [CrossRef]

53. Thomsen, D.K. The association between rumination and negative affect: A review. Cogn. Emot. 2006, 20, 1216-1235. [CrossRef]

54. Hobfoll, S.E. Conservation of resources: A new attempt at conceptualizing stress. Am. Psychol. 1989, 44, 513-524. [CrossRef]

55. Van Woerkom, M.; Bakker, A.B.; Nishii, L.H. Accumulative job demands and support for strength use: Fine-tuning the job demands-resources model using conservation of resources theory. J. Appl. Psychol. 2016, 101, 141-150. [CrossRef]

56. Fredrickson, B.L.; Mancuso, R.A.; Branigan, C.; Tugade, M.M. The undoing effect of positive emotions. Motiv. Emot. 2000, 24, 237-258. [CrossRef] [PubMed]

57. Fredrickson, B.L. The role of positive emotions in positive psychology: The broaden-and-build theory of positive emotions. Am. Psychol. 2001, 56, 218-226. [CrossRef] [PubMed]

58. Brislin, R.W. The Wording and Translation of Research Instrument. In Field Methods in Cross-Cultural Research; Lonner, W.J., Berry, J.W., Eds.; Sage: Beverly Hills, CA, USA, 1986; pp. 137-164.

59. Schwarzer, R.; Born, A.; Iwawaki, S.; Lee, Y.-M. The assessment of optimistic self-beliefs: Comparison of the Chinese, Indonesian, Japanese, and Korean versions of the General Self-Efficacy scale. Psychol. Int. J. Psychol. Orient 1997, 46, 69-88.

60. Pugh, S.D.; Groth, M.; Hennig-Thurau, T. Willing and able to fake emotions: A closer examination of the link between emotional dissonance and employee well-being. J. Appl. Psychol. 2011, 96, 377-390. [CrossRef]

61. Farmer, S.M.; Tierney, P.; Kung-Mcintyre, K. Employee creativity in Taiwan: An application of role identity theory. Acad. Manag. J. 2003, 46, 618-630.

62. Fiss, P.C. A set-theoretic approach to organizational configurations. Acad. Manag. Rev. 2007, 32, 1180-1198. [CrossRef]

63. Ragin, C.C. Redesigning Social Inquiry: Fuzzy Sets and Beyond.; University of Chicago Press: Chicago, IL, USA, $2008 ; 225$.

64. Ragin, C.C. Set Relations in social research: Evaluating their consistency and coverage. Political Anal. 2006, 14, 291-310. [CrossRef]

65. Gardner, H.K. Performance pressure as a double-edged sword: Enhancing team motivation but undermining the use of team knowledge. Adm. Sci. Q. 2012, 57, 1-46. [CrossRef]

66. Leung, K.; Huang, K.-L.; Su, C.-H.; Lu, L. Curvilinear relationships between role stress and innovative performance: Moderating effects of perceived support for innovation. J. Occup. Organ. Psychol. 2011, 84, 741-758. [CrossRef]

67. Sonnentag, S.; Fritz, C. Recovery from job stress: The stressor-detachment model as an integrative framework. J. Organ. Behav. 2015, 36 (Suppl. 1), S72-S103. [CrossRef]

68. Ohly, S.; Fritz, C. Work characteristics, challenge appraisal, creativity, and proactive behavior: A multi-level study. J. Organ. Behav. 2010, 31, 543-565. [CrossRef]

69. Markus, B.; Oldham, G.R. The curvilinear relation between experienced creative time pressure and creativity: Moderating effects of openness to experience and support for creativity. J. Appl. Psychol. 2006, 91, 963-970.

70. Whittington, J.L.; Bell, R.G. Leader-member exchange, enriched jobs, and goal-setting: Applying fuzzy set methodology. J. Bus. Res. 2016, 69, 1401-1406. [CrossRef]

(C) 2019 by the authors. Licensee MDPI, Basel, Switzerland. This article is an open access article distributed under the terms and conditions of the Creative Commons Attribution (CC BY) license (http:/ / creativecommons.org/licenses/by/4.0/). 